\title{
Profile of patients undergoing speech-language therapy in a physical and rehabilitation medicine hospital service
}

\author{
Paulo Prieto Farias ${ }^{1,2}$ \\ https://orcid.org/0000-0001-7875-8186 \\ Manuel Nibaldo del Campo Rivas ${ }^{3}$ \\ https://orcid.org/0000-0001-6076-2734
}

Universidad San Sebastián, Facultad de Ciencias de la Salud, Carrera de Fonoaudiología, Santiago de Chile, Chile. Hospital Clínico Dra. Eloísa Díaz I, La Florida, Servicio de Medicina Física y Rehabilitación, La Florida, Santiago de Chile, Chile.

${ }^{3}$ Universidad Santo Tomás, Facultad de Salud, Escuela de Fonoaudiología, Viña del Mar, Valparaíso, Chile.

Conflict of interests: Nonexistent



\section{ABSTRACT}

Purpose: to analyze the profile and risk factors of patients attended by speech therapists in a hospital service of physical and rehabilitation medicine (P\&RM) of the public health system.

Methods: a retrospective cohort study was carried out. The variables were summarized using frequencies, proportions, and measures of central tendency. Relative risks (RR) were estimated, using the incidence ratio (IC:95\%) and the bilateral Fisher's exact test. A level of significance was considered $p<0.05$.

Results: 23,365 speech therapy activities distributed in 8,416 sessions were carried out between September 2016 to September 2018, with patients admitted to a P\&RM service. The activities focused people over 60 years in the areas of swallowing (28.6\%) and cognition (11.7\%). Age equal to or greater than 60 years was identified as a risk factor for admission, due to cerebrovascular disease of 1.36 (95\% Cl: $1.24-$ $1.49 ; p=0.001$ ), and belonging to section $B$ of the National Health Fund (FONASA), 1.37 (95\% Cl: $1.29-1.46, p=0.001)$. The RR for respiratory pathology was greater in the winter period: 1.63 (95\% Cl: 1.50-1.76; $p=0.001)$.

Conclusion: elderly and low-income people are more likely to need speech therapy rehabilitation in the context of P\&RM service.

Keywords: Speech, Language and Hearing Sciences; Professional Practice; Physical and Rehabilitation Medicine; Aging; Risk Factors 


\section{INTRODUCTION}

The scope of the practice of speech therapists is broad, and the role in health adjusts to the legal provisions and epidemiological profiles of each country ${ }^{1,2}$. The service provision domains related to rehabilitation acts represent a strength of doing ${ }^{3}$, being the hospital activity working with the adult population a relevant area for experts in human communication and swallowing ${ }^{4-6}$.

The evidence indicates that speech therapy is essential in the approach of hospitalized patients with swallowing ${ }^{7}$, language and speech disorders ${ }^{8}$, subjects with neurocognitive disorders ${ }^{9,10}$, severe burns ${ }^{4}$, psychiatric patients ${ }^{11,12}$, and people who require rehabilitation in the various areas of the profession.

It is relevant to highlight that although one of the preferred results of the rehabilitation work is related to the functional performance of patients, there is also evidence regarding the contribution that rehabilitation work offers in reducing the time of hospital stay and the costs associated with health care ${ }^{13,14}$.

The Physical Medicine and Rehabilitation services (P\&RM services) represent units where interdisciplinary work is fundamental ${ }^{15,16}$, with medical, speech-language therapy, kinesiology, and occupational therapy equipment, among others, which represent instances where therapeutic efforts are focused on the recovery of patients ${ }^{17}$ from various units or hospital services ${ }^{18}$, functioning as a support unit within the health services.

The characteristics of the patients treated at the P\&RM service have been commonly described from a medical perspective, providing relevant information for decision-making in public health ${ }^{19,20}$. However, the type of patients, the number of care, the type of benefit, or the risk factors that contribute to their hospitalization or discharge, such as diagnosis, age, or severity of the disease, have not been detailed ${ }^{21-24}$ all of this, concerning the need to require speech therapy.

Having such information can contribute to the prioritization of human and material resources, provide a background for the opening of jobs, guide professional training and offer epidemiological information relevant to speech-language therapy work in the hospital context.

This research aimed to analyze the profile and risk factors of patients attended by speech therapists in a physical and rehabilitation medical service of a complex hospital of the public health system.

\section{METHODS}

This research was approved by the Scientific Research Committee of the Dr. Eloísa Díaz Clinical Hospital of La Florida, in Santiago de Chile, Chile. A retrospective cohort study was carried out, examining the monthly statistical data (MSD) of patients attended by speech therapists from the P\&RM service of the hospital center.

The universe was made up of all the patients who received speech therapy in the service from September 2016 to September 2018. Considering that the study contemplated secondary sources, all the patients who were enrolled in the REM were included.

The inclusion criteria were to have complete registry information: gender, age, service of origin, medical diagnosis, health forecast, REM diagnosis, and type of speech therapy. As an exclusion criterion, the following was determined: the record of care that did not include speech therapists.

The statistical analysis contemplated the frequency count and use of central tendency measures according to the nature of the variables. The determination of normality was carried out through the skewnesskurtosis test, considering a level of significance $p$ $<0.05$. The analysis of risk factors was carried out from the calculation of Relative Risks (RR), considering a $95 \% \mathrm{Cl}$ and a bilateral Fisher's exact test equal to or less than 0.05 .

The databases were obtained from the hospital statistics department, and no direct information was used from the clinical records of the patients for triangulation purposes.

The information was tabulated in Microsoft Excel 2010 and analyzed in Stata Statistical Software 14 (College Station, TX: StataCorp LP).

\section{RESULTS}

Between September 2016 and September 2018, the P\&RM service performed 8,416 speech therapy services to hospitalized patients (Figure 1), with a base staff of 132 professional hours per week. 


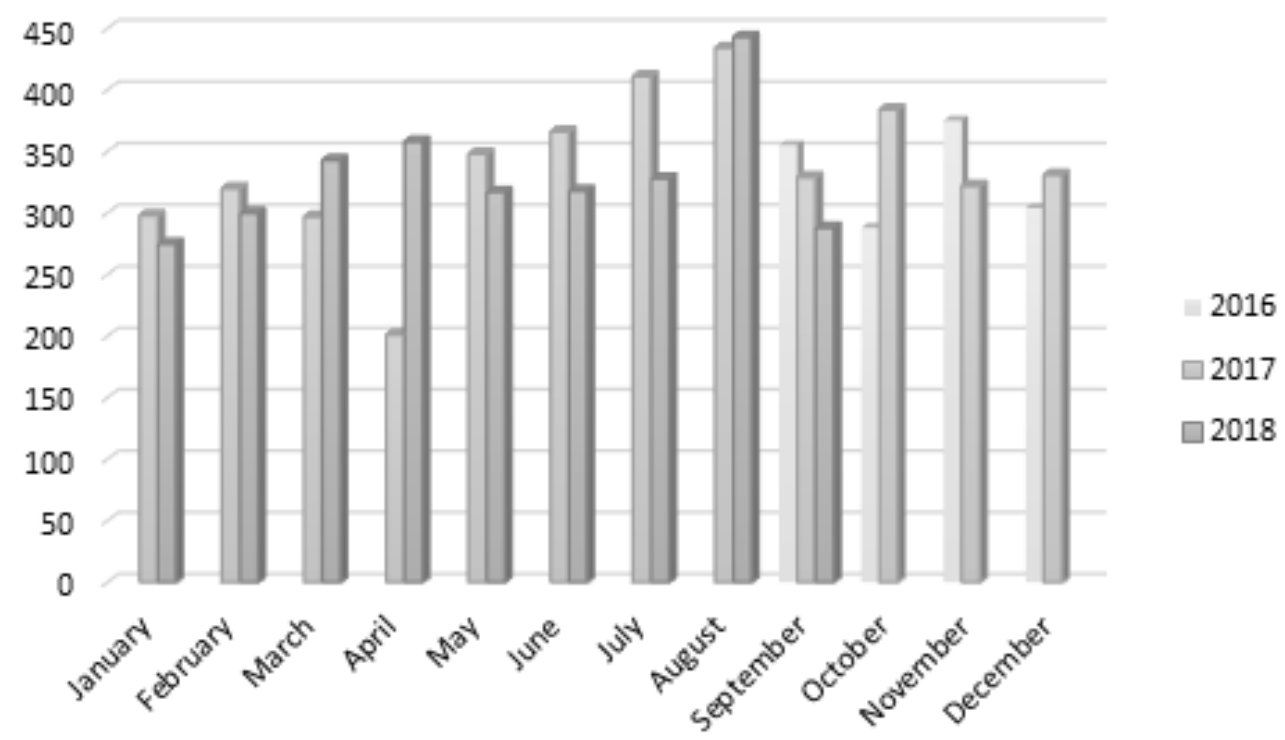

Figure 1. Frequency of speech therapy services from September 2016 to September 2018

After the initial review of the data, $99.03 \%$ of them were validated. $50.01 \%$ of patients were female, and $49.9 \%$ male.

The ages of hospitalized patients included people between the ages of 16 and 80 or older. Speech therapy services were concentrated on subjects aged 60 years or over; it should be noted that $37 \%$ of the services were made to individuals over 80 years of age.

The monthly average of speech therapy services delivered to the cohort was 431.8. Regarding the nature of these actions, $18.29 \%$ corresponded to new admissions, and the remaining $81.71 \%$ to therapeutic intervention activities.

The majority of patients (69.7\%) were concentrated in the National Health Fund (FONASA) belonging to section $B$-that is, individuals with monthly taxable income less than or equal to 250,000 Chilean pesos (CLP). A marginal number corresponded to subjects without health insurance (4.03\%), to indigent patients, or those who caused family subsidies (Law 18,020) (belonging to section A of FONASA). The rest of the people were located in sections $C$ and $D$-that is, monthly taxable income greater than CLP 250,000 and less than or equal to CLP 365,000 and subjects who receive a monthly taxable income greater than CLP 365,001 , respectively.

Regarding the service of intra-hospital origin of the patients, $49.9 \%$ came from the medium care unit (UCM), 36.59\% from the medical-surgical unit (MSU), $13.01 \%$ from the Critical Patient Unit (CPU), and 0.5\% from Day Hospital (DH).

The diagnoses of the patients were coded according to the monthly statistical data (MSD) used in the Chilean Health Services (HS), noting a significant proportion of people who required speech therapy due to respiratory pathology $(22.21 \%)$, disease cerebrovascular (34.25\%) or other (37.12\%) (Figure 2). 


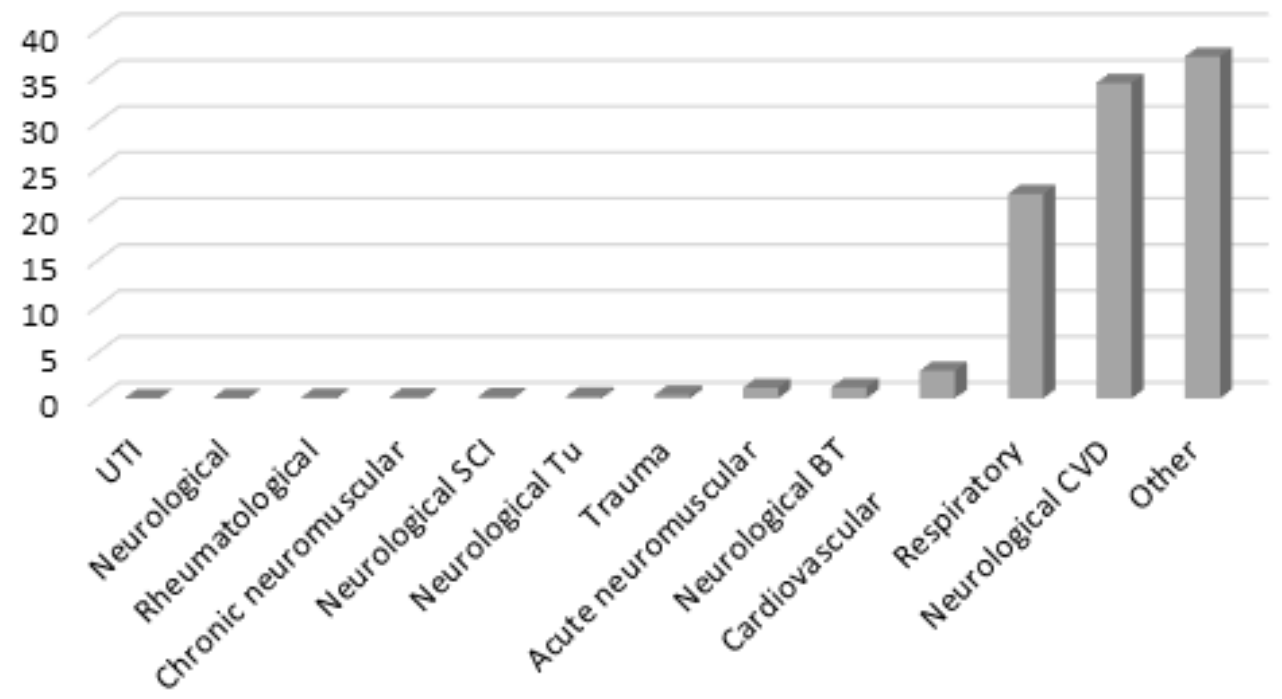

Captions: UTI = Urinary Tract Infection; Neurological SCI = Neurological Spinal Cord Injury; Neurological Tu= Neurological tumor; Neurological BT = Neurological Brain Trauma; Neurological CVD = Neurological Cerebrovascular Disease.

Figure 2. Ratio of diagnoses, according to monthly statistical registry of users attended in the Physical and Rehabilitation Medicine service

The analyzed cohort received 23,365 speech therapy services, with an average of 2.77 per session. Most of these actions corresponded to evaluation activities $(17.3 \%)$ or swallowing rehabilitation $(28.6 \%)$, followed by cognitive stimulation (11.7\%). Non-specific actions such as recreational activities or group education have a considerably low occurrence $(0.1 \%)$, noting that the tasks related to the disciplinary area of voice show a low occurrence $(3.5 \%$ for evaluation and $2.6 \%$ for rehabilitation) (Figure 3).

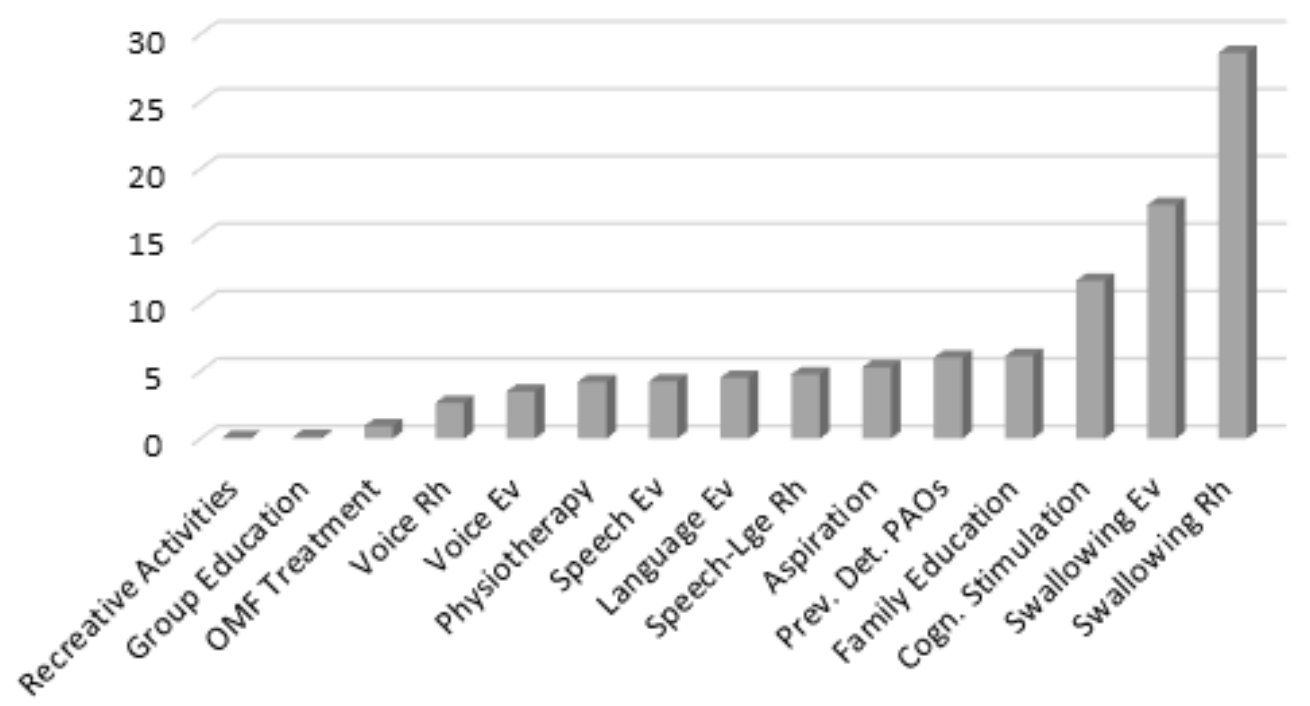

Captions: Rec. Activities = Recreative Activities; OMF Treatment = Treatment of Oral Motor Functions; Rh = Rehabilitation; Ev = Evaluation; Lge $=$ Language; Prev. Det. PAOs $=$ Prevention of Deterioration of Phonoarticulatory Organs; Cogn. Stimulation $=$ Cognitive Stimulation .

Figure 3. Ratio of speech therapy activities of the Physical and Rehabilitation Medicine service 
In the case of cerebrovascular disease (CVD), it was noted that the RR of admission with this diagnosis in people aged 60 years and over is $1.36(95 \% \mathrm{Cl}$ : 1.24-1.49; $p=0.001$ ), compared to subjects of another age range. The $R R$ of requiring rehabilitation due to CVD in people belonging to section $\mathrm{B}$ of the FONASA is 1.37 (95\% Cl: 1.29-1.46; $p=0.001$ ), compared to subjects from other sections (A, B, D, without anticipation) and for diagnoses coded as other diseases, a RR of 1.24 (95\% Cl: 1.17-1.32; $p=0.001$ ) was observed.

When analyzing the usability of rehabilitation services by month and type of REM diagnosis, a seasonal trend was observed, so diagnoses were stratified into trimesters. In this sense, it was noted that the RR to consult for respiratory disease was 0.55 (95\% Cl: $0.49-0.61 ; p=0.001$ ) from April to June and 1.63 (95\% Cl: $1.50-1.76 ; p=0.001)$ in the winter period (July-September quarter). In the case of CVD and other pathologies, the RR of its occurrence tends to decrease in the months of July to September with a RR of 0.76 (95\% Cl: $0.71-0.82 ; p=0.001)$ and $\mathrm{RR}=0.88(95 \% \mathrm{Cl}$ : $0.83-0.94 ; p=0.001$ ), respectively.

\section{DISCUSSION}

Age and socioeconomic status represents widely described risk factors for the development of various health problems that can impact the well-being of the population, morbidity, and mortality ${ }^{25}$.

This research shows that people over 60 years of age (Figure 2) and low-income (Figure 3) concentrate the work of speech therapy in the context of the P\&RM service, which is consistent with what is observed in other countries with elderly populations ${ }^{26}$. Likewise, a concentration of hospitalized patients aged 80 years or older was noted, which is expected in a public service specialized in musculoskeletal and neurological conditions that compromise functionality and quality of life, disorders whose incidence is higher in older people.

Given that the analyzed population comes from various hospital services, it is essential to mention that speech therapy work in the P\&RM service represents a second line of care, after patients have, for example, overcome a critical state of health, have graduated from intermediate care or come from a medical-surgical unit with conditions that cannot be resolved through outpatient consultations.

There is a coincidence with previous studies regarding the speech therapy actions related to the approach to swallowing and/or cognition of the hospitalized person even though they are services of different complexity ${ }^{23}$, dominating the swallowing evaluation and rehabilitation actions in the first instance what It is consistent with the casuistry of cerebrovascular disease and other pathologies of neurological origin reported in the cohort. The low report of evaluation activities and/or rehabilitation of language and speech (14\% in total) in the P\&RM service is explained that these actions are usually downloaded in the polyclinic, attached specialty office, and/or less complex care services in the outpatient setting.

Regarding the low occurrence of speech therapy actions related to voice, it is essential to note that in general, these activities are carried out as individual benefits aimed at non-hospitalized patients following international literature ${ }^{27,28}$ and that problems related to invasive orotracheal intubation injuries they are usually handled in UPC ${ }^{29,30}$.

Progressively, the evidence regarding speech therapy in the field of cognitive stimulation ${ }^{31}$ has been strengthened, even though there is still controversy regarding disciplinary overlap with occupational therapy, psychology, and/or kinesiology ${ }^{32,33}$. The above offers development perspectives where the transdisciplinary can be an opportunity.

The estimation of relative risks made it possible to identify factors related to patients with sequelae of CVD who receive speech therapy. This must be interpreted in the context of the health device studied since the public system and the National Health Fund (FONASA) cover the population with the lowest income in Chile $^{34}$. Regarding the seasonality observed in the requirement for speech therapy in the cohort, the literature indicates that there are environmental determinants that may influence the behavior of patients seeking medical or rehabilitation services ${ }^{35,36}$ due to respiratory exacerbations, heart attacks, or cerebrovascular disease, among others ${ }^{37-39}$. However, there is no evidence related to the association between these factors and the provision of care by speech therapists, which is considered a precedent for future research.

A limitation of this study is the local nature. Even though an extensive database was available, there is heterogeneity in the territorial, environmental, cultural, and economic characteristics of the adult population, so this background must be interpreted in the context of the informed cohort. On the other hand, it is known that retrospective studies have the disadvantage of estimating incidences with little precision. 
As a perspective, it is proposed to carry out multicenter studies and the analyzes which do not only describe profiles, but which can also evaluate costeffectiveness, risk factors, and causality related to the determinants that influence the disorders that compromise human communication and swallowing in patients who require specialized care in physical medicine and rehabilitation services.

\section{CONCLUSION}

The profile of patients assisted in the P\&RM service corresponds to the adult population, mainly over 60 years of age, diagnosed with respiratory, neurological, or other diseases that belong to a low socioeconomic level. Among the relevant risk factors regarding the need to require speech therapy are: age, socioeconomic level, and MSD diagnosis.

Although a seasonal behavior was observed in the provision of speech therapy services, it is essential to identify periods where patients' flow increases, to assess whether the professional staff can provide adequate coverage to patients or whether it is necessary to strengthen the staff of professionals to safeguard quality.

Even when speech therapy work is described in terms of rehabilitation in Chile, little evidence is available regarding the patients' profile, access to comprehensive rehabilitation, its effectiveness, user satisfaction, and continuity of support, among other issues, aspects that the profession must address systematically.

The generation of epidemiological profiles will contribute to the scope of a provision of services that can be adjusted to the characteristics of the patients and that allow improving the management of prioritization of resources and the generation of clinical guidelines based on evidence. This will also allow for a structural improvement in how speech pathologists are integrated into multidisciplinary teams at the hospital level, helping to improve the quality of life and functionality of the patients they accompany.

\section{REFERENCES}

1. ASHA: American Speech-Languaghe-Hearing Association. Scope of practice in speech-language pathology [journal on the internet]. 2016 [accessed on 2020 jun 22]. Available at: http://www.asha.org/ policy/SP2016-00343/\#Framework
2. Vega $Y$, Rodríguez $M$, del Campo M. Análisis del rol del fonoaudiólogo(a) en el sector salud en Chile. Cienc Amp Trab [journal on the internet]. 2017 [accessed on 2020 jun 22]; 19(59):76-80. Available at: http://dx.doi.org/10.4067/ S0718-24492017000200076

3. Pietsch K, Lyon T, Dhillon V. Speech language pathology rehabilitation. Med Clin North Am [journal on the internet]. 2018 [accessed on 2020 aug 12]; 102(6):1121-34. Available at: https://pubmed.ncbi. nlm.nih.gov/30342613/

4. Rumbach $A$, Clayton N, Muller M, Maitz $P$. The speech-language pathologist's role in multidisciplinary burn care: an international perspective. Burns $\mathrm{J}$ Int Soc Burn Inj [journal on the internet]. 2016 [accessed on 2020 Jan 6]; 42(4):863-71. Available at: https://pubmed.ncbi. nlm.nih.gov/26822697/

5. Brougham R, David D, Adornato V, Gordan W, Dale B, Georgeadis A et al. Speech-language pathology treatment time during inpatient spinal cord injury rehabilitation: the SCIRehab project. J Spinal Cord Med [journal on the internet]. 2011 [accessed on 2020 aug 12]; 34(2):186-95. Available at: https:// www.ncbi.nlm.nih.gov/pmc/articles/PMC3066498/

6. Lawton M, Sage K, Haddock G, Conroy P, Serrant L. Speech and language therapists' perspectives of therapeutic alliance construction and maintenance in aphasia rehabilitation post-stroke. Int $\mathrm{J}$ Lang Commun Disord [journal on the internet]. 2018 [accessed on $2020 \mathrm{Jul} 15]$ ] 53(3):550-63. Available at: https://pubmed.ncbi.nlm.nih.gov/29349881/

7. Wiberg S, Whitling S, Bergström L. Tracheostomy management by speech-language pathologists in Sweden. Logoped Phoniatr Vocol [journal on the internet]. 2020 [accessed on 2021 Jan 14]; 45(4):1-11. Available at: https://doi.org/10.1080/140 15439.2020.1847320

8. Manning M, MacFarlane A, Hickey A, Franklin S. Perspectives of people with aphasia post-stroke towards personal recovery and living successfully: a systematic review and thematic synthesis. PLoS ONE [journal on the internet]. 2019 [accessed on 2021 Jan 21]; 14(3):e0214200. Available at: https:// www.ncbi.nlm.nih.gov/pmc/articles/PMC6430359/ 
9. Timmons S, O'Shea E, O'Neill D, Gallagher P, de Siún A, McArdle $D$ et al. Acute hospital dementia care: results from a national audit. BMC Geriatr [journal on the internet]. 2016 [accessed on 2020 Jul 12]; 16(113):1-10. Available at: https:// bmcgeriatr.biomedcentral.com/articles/10.1186/ s12877-016-0293-3

10. Volkmer A, Rogalski E, Henry M, Taylor-Rubin $C$, Ruggero L, Khayum $R$ et al. Speech and language therapy approaches to managing primary progressive aphasia. Pract Neurol [journal on the internet]. 2020 [accessed on 2020 Jan 09]; 20(2):154-61. Available at: https://www.ncbi.nlm. nih.gov/pmc/articles/PMC6986989/

11. Muir NJ. The role of the speech and language therapist in psychiatry. Psychiatr Bull [journal on the internet]. 1996 [accessed on 2020 Jan 09]; 20(9):524-6. Available at: http:// citeseerx.ist.psu.edu/viewdoc/download? $\mathrm{doi}=10 \cdot 1 \cdot 1 \cdot 558.3636 \& \mathrm{rep}=$ rep $1 \&$ type $=$ pdf

12. Mac-Kay A, Mondaca I, Monardez P. Speechlanguage intervention in schizophrenia: an integrative review. Rev. CEFAC [journal on the internet]. 2018 [accessed on 2020 Aug 03]; 20(2):238-46. Available at: https://doi. org/10.1590/1982-0216201820219317

13. Bowen A, Hesketh A, Patchick E, Young A, Davies L, Vail $A$ et al. Clinical effectiveness, cost-effectiveness and service patients' perceptions of early, well-resourced communication therapy following a stroke: a randomised controlled trial (the ACT NoW Study). Health Technol Assess Winch Engl [journal on the internet]. 2012 [accessed on 2020 Nov 09]; 16(26):1-160. Available at: https://pubmed.ncbi. nlm.nih.gov/22613690/

14. Silva D, Lira F, Oliveira J, Canuto M. Speech therapy practice in the intensive care unit of a hospital of infectious diseases of Alagoas. Rev. CEFAC [journal on the internet]. 2016 [accessed on 2020 Aug 11]; 18(1):174-83. Available at: https:// doi.org/10.1590/1982-0216201618112015

15. Beaulieu C, Dijkers P, Barrett R, Horn S, Giuffrida C, Timpson $\mathrm{M}$ et al. Occupational, physical, and speech therapy treatment activities during inpatient rehabilitation for traumatic brain injury. Arch Phys Med Rehabil [journal on the internet]. 2015 [accessed on $2020 \mathrm{Jul} \mathrm{17];} \mathrm{96(80):S222-S234.}$ e17. Available at: https://pubmed.ncbi.nlm.nih. gov/26212399/
16. Hardin KY, Kelly JP. The role of speech-language pathology in an Interdisciplinary Care Model for persistent symptomatology of mild traumatic brain injury. Semin Speech Lang [journal on the internet]. 2019 [accessed on 2020 Oct 21]; 40(1):65-78. Available at: https://pubmed.ncbi.nlm. nih.gov/30616296/

17. Karges J, Smallfied S. A description of the outcomes, frequency, duration, and intensity of occupational, physical, and speech therapy in inpatient stroke rehabilitation. J Allied Health [journal on the internet]. 2009 [accessed on 2020 Aug 18]; 38(1):E1-10. Available at: https://pubmed. ncbi.nlm.nih.gov/19753406/

18. Mizuochi K. Rehabilitation medicine in the acute care setting in Japan. Jpn Med Assoc J JMAJ [journal on the internet]. 2012 [accessed on 2020 Apr 12]; 55(3):246-52. Available at: https://pubmed. ncbi.nlm.nih.gov/25237225/

19. O'Young B, Gosney J, Ahn C. The concept and epidemiology of disability. Phys Med Rehabil Clin $\mathrm{N}$ Am [journal on the internet]. 2019 [accessed on 2020 Apr 13]; 30(4):697-707. Available at: https:// pubmed.ncbi.nlm.nih.gov/31563163/

20. Varma $P$, Stineman MG, Dillingham TR. Physical medicine and rehabilitation clinics of North America epidemiology of limb loss. Phys Med Rehabil Clin $\mathrm{N} \mathrm{Am}$ [journal on the internet]. 2014 [accessed on 2020 Aug 09]; 25(1):1-8. Available at: https://www. ncbi.nlm.nih.gov/pmc/articles/PMC4533906/

21. Lavados PM, Sacks C, Prina L, Escobar A, Tossi $\mathrm{C}$, Araya $\mathrm{F}$ et al. Incidence, 30-day case-fatality rate, and prognosis of stroke in lquique, Chile: a 2-year community-based prospective study (PISCIS project). Lancet Lond Engl [journal on the internet]. 2005 [accessed on 2020 Dic 25]; 365(9478):2206-15. Available at: https://pubmed. ncbi.nlm.nih.gov/15978929/

22. Peña-Chávez R, López-Espinoza M, GuzmánInostroza M, Jara-Parra M, Sepúlveda-Arriagada $C$, Sepulveda-Arriagada $C$ et al. Factors associated with post-stroke oropharingeal dysphagia. Rev Neurol [journal on the internet]. 2015 [accessed on 2020 Jan 07]; 61(7):295-300. Available at: https:// pubmed.ncbi.nlm.nih.gov/26411273/ 
23. del Campo M, Estay P, Valencia G, Muñoz P, Arce $K$, Silva-Ríos A. Profile of patients receiving speechlanguage therapy service at a critical patient unit. Rev. CEFAC [journal on the internet]. 2021 [accessed on 2021 Jan 21]; 23(1):1-7. Available at: $\quad$ http://www.scielo.br/scielo.php?script $=$ sci_ abstract\&pid $=$ S1516-18462021000100502\&lng $=e$ n\&nrm =iso\&tlng $=$ en

24. del Campo $M$, Alarcon $K$, Escobar $M$, Bañados $Y$, Silva-Ríos A. Evaluación económica del costo de estadía hospitalaria en una unidad de paciente crítico. Cienc Enferm [journal on the internet]. 2020 [accessed on 2021 Jan 21]; 26(1):1-8. Available at: https://scielo.conicyt.cl/scielo.php?script $=$ sci_ abstract\&pid=S0717-95532020000100214\&Ing=e s\&nrm=iso\&tlng $=e s$

25. Zhang C-Q, Chung P-K, Zhang R, Schüz B. Socioeconomic inequalities in older adults' health: the roles of neighborhood and individual-level psychosocial and behavioral resources. Front Public Health [journal on the internet]. 2019 [accessed on 2021 Jan 21]; 7(318):1-4. Available at: https://www.ncbi.nlm.nih.gov/pmc/articles/ PMC6823619/

26. Santiago L, Graça CL, Rodrigues M, Santos G. Characterization of the elderly health in a speech and language therapy perspective. Rev. CEFAC [journal on the internet]. 2016 [accessed on $2020 \mathrm{Jul}$ 12]; 18(5):1088-96. Available at: https://www.scielo. $\mathrm{br} / \mathrm{scielo}$.php? script $=$ sci_arttext\&pid $=$ S1516$18462016000501088 \&$ Ing $=$ en\&nrm $=$ iso\&tlng $=$ pt\& ORIGINALLANG $=\mathrm{pt}$

27. Lyberg-Åhlander V, Rydell R, Fredlund $P$, Magnusson $\mathrm{C}$, Wilén $\mathrm{S}$. Prevalence of voice disorders in the general population, based on the Stockholm Public Health Cohort. J Voice [journal on the internet]. 2019 [accessed on 2020 Nov 02]; 33(6):900-5. Available at: https://pubmed.ncbi.nlm. nih.gov/30126692/

28. Bhattacharyya $\mathrm{N}$. The prevalence of voice problems among adults in the United States. The Laryngoscope [journal on the internet]. 2014 [accessed on 2020 Aug 12 2]; 124(10):2359-62. Available at: https://pubmed.ncbi.nlm.nih. gov/24782443/
29. Brodsky MB, Levy MJ, Jedlanek E, Pandian V, Blackford $B$, Price $C$ et al. Laryngeal injury and upper airway symptoms after oral endotracheal intubation with mechanical ventilation during critical care: a systematic review. Crit Care Med [journal on the internet]. 2018 [accessed on 2020 Aug 12]; 46(12):2010-7. Available at: https://pubmed.ncbi. nlm.nih.gov/30096101/

30. Fialkow L, Farenzena M, Wawrzeniak I, Brauner $\mathrm{J}$, Vieira S, Vigo A et al. Mechanical ventilation in patients in the intensive care unit of a general university hospital in southern Brazil: an epidemiological study. Clinics [journal on the internet]. 2016 [accessed on 2020 Jan 12]; 71(3):145-51. Available at: https://www.ncbi.nlm. nih.gov/pmc/articles/PMC4785851/

31. Swan K, Hopper M, Wenke R, Jackson C, Till T, Conway E. Speech-language pathologist interventions for communication in moderatesevere dementia: a systematic review. Am J Speech Lang Pathol [journal on the internet]. 2018 [accessed on 2020 Feb 14]; 27(2):836-52. Available at: https://pubmed.ncbi.nlm.nih.gov/29554196/

32. Yuill N, Hollis V. A systematic review of cognitive stimulation therapy for older adults with mild to moderate dementia: an occupational therapy perspective. Occup Ther Int [journal on the internet]. 2011 [accessed on 2020 Aug 15]; 18(4):163-86. Available at: https://pubmed.ncbi. nlm.nih.gov/21425381/

33. Woods B, Aguirre E, Spector AE, Orrell M. Cognitive stimulation to improve cognitive functioning in people with dementia. Cochrane Dementia and Cognitive Improvement Group, editor. Cochrane Database Syst Rev [journal on the internet]. 2012 [accessed on 2021 Jan 21]; 2012(2):1-56. Available at: http:// doi.wiley.com/10.1002/14651858.CD005562. pub2

34. Becerril-Montekio V, Reyes JD, Manuel A. Sistema de salud de Chile. Salud Pública México [journal on the internet]. 2011 [accessed on 2020 Oct 04]; 53:s132-42. Available at: http:// www.scielo.org.mx/scielo.php? script $=$ sci arttext\&pid $=$ S0036-36342011000800009

35. Wong TW. Association between air pollution and general practitioner visits for respiratory diseases in Hong Kong. Thorax [journal on the internet]. 2006 [accessed on 2020 Jul 21]; 61(7):585-91. Available at: https://pubmed.ncbi.nlm.nih.gov/16537667/ 
36. Luo L, Hudson LG, Lewis J, Lee J-H. Two-step approach for assessing the health effects of environmental chemical mixtures: application to simulated datasets and real data from the Navajo Birth Cohort study. Environ Health [journal on the internet]. 2019 [accessed on 2019 Jun 14]; 18(46):1-16. Available at: https:// ehjournal.biomedcentral.com/articles/10.1186/ s12940-019-0482-6

37. Du Y, Xu X, Chu M, Guo Y, Wang J. Air particulate matter and cardiovascular disease: the epidemiological, biomedical and clinical evidence. J Thorac Dis [journal on the internet]. 2016 [accessed on 2020 Dec 25]; 8(1):E8-19. Available at: https:// doi.org/10.3978/j.issn.2072-1439.2015.11.37

38. Loane C, Pilinis C, Lekkas TD, Politis M. Ambient particulate matter and its potential neurological consequences. Rev Neurosci [journal on the internet]. 2013 [accessed on 2019 Jun 14]; 24(3):323-35. Available at: https://www.degruyter. $\mathrm{com} / \mathrm{view} / \mathrm{j} /$ revneuro.2013.24.issue-3/revneuro2013-0001/revneuro-2013-0001.xml

39. Ko F, Hui D. Air pollution and chronic obstructive pulmonary disease: air pollution and COPD. Respirology [journal on the internet]. 2012 [accessed on 2020 Aug 03]; 17(3):395-401. Available at: https://pubmed.ncbi.nlm.nih. gov/22142380/ 